\title{
Central Autonomic Regulation Assessed by Pupillary Light Reflex is Impaired in Children With Attention Deficit Hyperactivity Disorder
}

\author{
Andrea HAMRAKOVA ${ }^{1,2}$, Igor ONDREJKA ${ }^{2}$, Nikola SEKANINOVA ${ }^{1,3}$, Lucia BONA \\ OLEXOVA $^{1,3}$, Zuzana VISNOVCOVA ${ }^{1,3}$, Dana CESNEKOVA ${ }^{2}$, Igor HRTANEK ${ }^{2}$, Miloslav \\ OPPA $^{2}$, Peter HUTKA ${ }^{2}$, Ingrid TONHAJZEROVA ${ }^{1,3}$
}

${ }^{1}$ Department of Physiology, Jessenius Faculty of Medicine in Martin, Comenius University in Bratislava, Martin, Slovak Republic, ${ }^{2}$ Clinic of Psychiatry, Jessenius Faculty of Medicine in Martin, Comenius University in Bratislava, Martin and University Hospital in Martin, Slovak Republic, ${ }^{3}$ Biomedical Center Martin, Jessenius Faculty of Medicine in Martin, Comenius University in Bratislava, Martin, Slovak Republic

Received March 30, 2020

Accepted October 6, 2020

\section{Summary}

It is assumed that the Attention Deficit Hyperactivity Disorder is associated with the central autonomic dysregulation, however, the studies are rare. Analysis of pupillary light reflex represents a non-invasive tool to provide information related to the central autonomic regulation; thus, we aimed to evaluate potential disturbances in the central autonomic integrity using pupillary light reflex examination in Attention Deficit Hyperactivity Disorder. We have examined 20 children with Attention Deficit Hyperactivity Disorder (10 boys, 13.0 2.3 years) and 20 age/gender-matched healthy subjects. Pupillary light reflex was examined at rest for both eyes using Pupillometer PLR-2000 (NeurOptics, USA). Evaluated parameters were: diameter of the pupil before the application of light stimulus and after illumination at the peak of the constriction, the percentual change of the pupil diameter during constriction, average constriction velocity, maximum constriction velocity and average dilation velocity. We found significantly lower percentual change of the pupil diameter during constriction for both eyes in Attention Deficit Hyperactivity Disorder group compared to controls (right eye: $-25.81 \pm 1.23 \%$ vs. $-30.32 \pm 1.31 \%, \mathrm{p}<0.05$, left eye: $-25.44 \pm 1.65 \%$ vs. $-30.35 \pm 0.98 \%, p<0.05)$. The average constriction velocity and maximum constriction velocity were significantly shortened in left eye in Attention Deficit Hyperactivity Disorder group compared to controls $(p<0.05)$. Our findings revealed altered pupillary light reflex indicating abnormal centrally-mediated autonomic regulation characterized by parasympathetic underactivity associated with relative sympathetic predominance in children suffering from Attention Deficit Hyperactivity Disorder.

\section{Key words}

Central autonomic regulation - Pupillary light reflex • Attention Deficit Hyperactivity Disorder

\section{Corresponding author}

I. Tonhajzerova, Department of Physiology and Biomedical Center Martin, Jessenius Faculty of Medicine in Martin, Comenius University in Bratislava, Mala Hora 4C, 036 01, Martin, Slovak Republic. E-mail: tonhajzerova@jfmed.uniba.sk, ingridtonhajzerova@gmail.com

\section{Introduction}

Attention Deficit Hyperactivity Disorder (ADHD) is one of the most commonly diagnosed developmental disorders in childhood characterized by hyperactivity, impulsivity and inattention (Faraone et al. 2015). Previous studies indicated that ADHD is associated with an autonomic imbalance leading to higher risk of negative health outcomes (Shibagaki et al. 1993, Lazzaro et al. 1999, Crowell et al. 2006, Tonhajzerova et al. 2014). Several studies focusing on examining the relationship between the autonomic nervous system (ANS) and ADHD have assessed various physiological parameters (Shibagaki et al. 1993, Lazzaro et al. 1999, 
Crowell et al. 2006, Tonhajzerova et al. 2009, Tonhajzerova et al. 2014). Previous studies revealed ADHD linked autonomic imbalance - low parasympathetic activity and relative sympathetic overactivity indexed by decreased complex heart rate variability (Tonhajzerova et al. 2009, Tonhajzerova et al. 2014). In contrast, electrodermal activity, as an index of sympathetic cholinergic regulation, was attenuated in ADHD patients compared to healthy subjects indicating potential sympathetic hypoarousal in ADHD (Shibagaki et al. 1993, Lazzaro et al. 1999). However, studies related to central autonomic control indexed by pupil changes in ADHD are rare.

The pupillary light reflex (PLR) describes the constriction and subsequent dilation of the pupil in response to light as a result of the antagonistic actions of the iris sphincter and dilator muscles, whereas these muscles are regulated by both ANS branches (Hall and Chilcott 2018). The parasympathetic center for pupillary constriction, the Edinger-Westphal nucleus, is activated by the light falling on retinal ganglion cells and consequent activation of pretectal olivary nucleus located in the midbrain. This action results in generation of action potentials through the oculomotor nerves innervating the ciliary ganglion and leads to the activation of the iris sphincter muscle via the neurotransmitter acetylcholine resulting in pupil constriction (McDougal and Gamlin 2015, Hall and Chilcott 2018). The parasympathetic innervation of the iris sphincter muscle is suppressed by central supranuclear inhibition of Edinger-Westphal nucleus via $\alpha 2$-adrenergic receptor activation resulting in pupil dilation. In addition, the iris dilator muscle contracts via excitation of the $\alpha 1$-adrenergic sympathetic pathway (Hall and Chilcott 2018). Thus, the pupillary dilation is result of a stimulation of the dilator regulated by sympathetic activity or an inhibition of constrictor innervated by parasympathetic nervous system (Laeng et al. 2012). Taken together, the constriction of pupil also called "miosis" is mediated by the action of sphincter muscle under parasympathetic control, whereas pupillary dilation or "mydriasis" is managed by dilator muscle under sympathetic control or by an inhibition of constrictor (Laeng et al. 2012, Hall and Chilcott 2018). Since both parts of pupillary reflex are regulated by different components of the ANS, the PLR parameters could be used as indicators for either sympathetic or parasympathetic modulation (Hall and Chilcott 2018). Further, recent studies have shown that pupillary reactivity is influenced by several factors such as attention, emotional regulation and cognitive processing (Binda et al. 2013, Köles 2017), which abnormalities are related to ADHD (Faraone et al. 2015). Thus, it is assumed that the pathway of the PLR provides an optimal model for investigating central autonomic regulation in mental disorders (Mestanikova et al. 2017, Sekaninova et al. 2019).

Clinical studies related to pupil changes in children suffering from ADHD are rare. The first study investigating pupil changes in children was conducted by Zahn et al. (1978) reporting smaller pupil dilation to visual stimulus in children with minimal brain dysfunction. However, Kara et al. (2013) showed no significant differences in pupil diameters between children with ADHD and healthy subjects, thus, this question is still unclear. We hypothesized that children with ADHD will show impaired PLR induced by dysfunction of ANS. Thus, we aimed to study central autonomic control indexed by PLR in drug-naive children suffering from ADHD. To the best of our knowledge, it is the first study to evaluate central autonomic regulation assessed by PLR in children with ADHD.

\section{Methods}

\section{Subjects}

We have examined 20 children suffering from ADHD (10 boys, average age: $13.0 \pm 2.3$ years, body mass index $18.6 \pm 3.0 \mathrm{~kg} / \mathrm{m}^{2}$ ) prior to pharmacotherapy and 20 healthy subjects matched for gender and age (control group). The children suffering from ADHD were recruited from the inpatients admitted to the Department of Children and Adolescent Psychiatry, Clinic of Psychiatry, University Hospital in Martin. The children were diagnosed according to Diagnostic and Statistical Manual of Mental Disorders, DSM-5 (American Psychiatric Association 2013) after being admitted to hospital by a child psychiatrist. Then, every child was examined by two independent specialists for confirmation of ADHD diagnosis. In addition, control participants have never been treated for any mental disorder. Strict exclusion criteria were used for both ADHD and control groups: ophtalmological diseases (except correctable vision), obesity, underweight, evidence of cardiovascular, respiratory, neurological, endocrine, metabolic or infectious diseases. All examined subjects were righthanded. 


\section{Ethics statement}

The study was approved by the Ethics Committee of the Jessenius Faculty of Medicine in Martin, Comenius University in Bratislava, the Slovak Republic. All procedures performed in our study were in accordance with the ethical standards of the institutional and national research committee and with the 1964 Helsinki declaration and its later amendments or comparable ethical standards. All children/patients/ guardians were carefully informed about the study protocol and informed written consent was obtained from them to participate in the study prior to examination.

\section{Study protocol}

All subjects were examined in a quiet room with the same light intensity under standard conditions (illumination: 200 lux, temperature: $22-23{ }^{\circ} \mathrm{C}$, humidity: $45-55 \%$ ) with the minimization of stimuli in the morning between 8:00 and 12:00 a.m. after breakfast. After $10 \mathrm{~min}$ of adaptation to the conditions of examination room the participants were instructed to sit comfortably and rest for $5 \mathrm{~min}$. Then, the parameters of PLR were measured separately for both eyes using a handheld infrared optical scanner Pupillometer PLR-2000 (NeurOptics, USA) with a sampling frequency $32 \mathrm{~Hz}$ and accuracy $0.1 \mathrm{~mm}$. During the measurement the participants were asked to keep their head straight, fix their gaze on a spot located at a distance of $3 \mathrm{~m}$ and keep both eyes wide open without blinking. The pupillometer was kept at a right angle to the subject's axis of vision without tilting of the device. The margins of the pupil were electronically detected under infrared illumination and tracked during $5 \mathrm{~s}$ of continuous recording of the pupil after application of light stimulus with intensity of $180 \mu \mathrm{W}$ and duration $154 \mathrm{~ms}$.

\section{Evaluated parameters}

The diameter of the pupil in millimeters was assessed before the application of light stimulus (initial value, INIT) and after illumination at the peak of the constriction (final value, END). The percentual change (DELTA) of the pupil diameter during constriction was calculated as DELTA $=($ INIT - END $) /$ INIT $\times 100 \%$. In addition, following parameters of the dynamics of PLR were assessed: average constriction velocity (ACV, $\mathrm{mm} / \mathrm{s}$ ), maximum constriction velocity ( $\mathrm{MCV}, \mathrm{mm} / \mathrm{s}$ ) and average dilation velocity after having reached the peak of the constriction (ADV, $\mathrm{mm} / \mathrm{s}$ ). Based on current knowledge, PLR parameters indicating predominantly parasympathetic activity are ACV, MCV and DELTA. INIT reflects combined activity of both ANS branches, and the ADV is considered to indicate sympathetic activity (Bär et al. 2005, Wang et al. 2016). The description of evaluated PLR parameters is summarized in Table 1.

Table 1. Description of the pupillary light reflex parameters.

\begin{tabular}{|c|c|c|c|}
\hline Parameter & Abbreviation & Description & Unit \\
\hline Initial diameter & INIT & $\begin{array}{l}\text { Diameter of the pupil before } \\
\text { application of light stimulus }\end{array}$ & $(\mathrm{mm})$ \\
\hline Final diameter & END & $\begin{array}{l}\text { Diameter of the pupil after } \\
\text { illumination at the peak of the } \\
\text { constriction }\end{array}$ & $(\mathrm{mm})$ \\
\hline $\begin{array}{l}\text { Percentual change of } \\
\text { constriction }\end{array}$ & $\begin{array}{c}\text { DELTA }=(\text { INIT }- \text { END }) / \\
\text { INIT } \times 100 \%\end{array}$ & $\begin{array}{l}\text { Percentual change of the pupil } \\
\text { diameter during constriction }\end{array}$ & $(\%)$ \\
\hline Average constriction velocity & $\mathrm{ACV}$ & $\begin{array}{l}\text { Average velocity of the pupil } \\
\text { constriction }\end{array}$ & $(\mathrm{mm} / \mathrm{s})$ \\
\hline Maximum constriction velocity & $\mathrm{MCV}$ & $\begin{array}{l}\text { Maximum velocity of the pupil } \\
\text { constriction }\end{array}$ & $(\mathrm{mm} / \mathrm{s})$ \\
\hline Average dilation velocity & $\mathrm{ADV}$ & $\begin{array}{l}\text { Average velocity of the pupil } \\
\text { dilatation after having reached the } \\
\text { peak of the constriction }\end{array}$ & $(\mathrm{mm} / \mathrm{s})$ \\
\hline
\end{tabular}

\section{Statistical analysis}

The data were analysed using statistical software package SYSTAT 10 (Cranes Software International Ltd,
USA). The non-Gaussian/Gaussian distribution was ascertained by Shapiro-Wilk normality test and all the data showed non-Gaussian distribution. Due to non- 
parametric distribution of data, the Kruskal-Wallis test was used for comparison between groups and Wilcoxon test for between eyes comparison. Data are expressed as mean \pm SEM. The probabilities $\mathrm{p}<0.05$ were considered as significant.

\section{Results}

Regarding both eyes, the parameter DELTA was significantly lower in ADHD compared to control group (right eye: $-25.81 \pm 1.23 \%$ vs. $-30.32 \pm 1.31 \%, \mathrm{p}<0.05$, left eye: $\quad-25.44 \pm 1.65 \% \quad$ vs. $\quad-30.35 \pm 0.98 \%, \quad \mathrm{p}<0.05)$. Moreover ACV and MCV were significantly shortened in ADHD group compared to control group for the left eye $(-3.61 \pm 0.19 \mathrm{~mm} / \mathrm{s} \quad$ vs. $\quad-4.16 \pm 0.14 \mathrm{~mm} / \mathrm{s}, \quad \mathrm{p}<0.05$ and $-4.59 \pm 0.28 \mathrm{~mm} / \mathrm{s} \quad$ vs. $\quad-5.33 \pm 0.20 \mathrm{~mm} / \mathrm{s}, \quad \mathrm{p}<0.05)$.
Regarding the right eye, these parameters - ACV, MCV showed tendency to significant differences in ADHD group compared to controls $(-4.18 \pm 0.18 \mathrm{~mm} / \mathrm{s}$ vs. $-3.68 \pm 0.20 \mathrm{~mm} / \mathrm{s}, \quad \mathrm{p}=0.06$ and $-4.89 \pm 0.56 \mathrm{~mm} / \mathrm{s} \quad \mathrm{vs}$. $-4.64 \pm 0.27 \mathrm{~mm} / \mathrm{s}, \mathrm{p}=0.07)$. No significant differences were found in the other parameters - INIT, END, and ADV for both eyes. All results are summarized in the Table 2. Regarding side differences between left and right eyes, no significant differences were found in children with ADHD for evaluated PLR parameters - INIT, END, DELTA, ACV, MCV, ADV ( $p=0.393, p=0.338, p=0.682$, $\mathrm{p}=0.408, \mathrm{p}=0.535, \mathrm{p}=0.139$ ). Similarly, there were no significant side differences in control group for PLR parameters - INIT, END, DELTA, ACV, MCV, ADV $(\mathrm{p}=0.552, \quad \mathrm{p}=0.955, \quad \mathrm{p}=0.716, \quad \mathrm{p}=0.778, \quad \mathrm{p}=0.809$, $\mathrm{p}=0.507)$.

Table 2. Parameters of the pupillary light reflex.

\begin{tabular}{|c|c|c|c|}
\hline & Controls $(n=20)$ & ADHD $(n=20)$ & p-value \\
\hline \multicolumn{4}{|l|}{ Left eye } \\
\hline $\operatorname{INIT}(\mathrm{mm})$ & $5.26 \pm 0.18$ & $5.29 \pm 0.27$ & 0.725 \\
\hline$E N D(m m)$ & $3.67 \pm 0.14$ & $3.93 \pm 0.23$ & 0.609 \\
\hline DELTA (\%) & $-30.35 \pm 0.98$ & $-25.44 \pm 1.65$ & $\mathrm{p}<0.05$ \\
\hline$A C V(\mathrm{~mm} / \mathrm{s})$ & $-4.16 \pm 0.14$ & $-3.61 \pm 0.19$ & $\mathrm{p}<0.05$ \\
\hline$M C V(\mathrm{~mm} / \mathrm{s})$ & $-5.33 \pm 0.20$ & $-4.59 \pm 0.28$ & $\mathrm{p}<0.05$ \\
\hline$A D V(\mathrm{~mm} / \mathrm{s})$ & $1.53 \pm 0.09$ & $1.42 \pm 0.11$ & 0.537 \\
\hline \multicolumn{4}{|l|}{ Right eye } \\
\hline INIT (mm) & $5.27 \pm 0.21$ & $5.39 \pm 0.26$ & 0.666 \\
\hline$E N D(m m)$ & $3.69 \pm 0.18$ & $3.99 \pm 0.20$ & 0.319 \\
\hline DELTA (\%) & $-30.32 \pm 1.31$ & $-25.81 \pm 1.23$ & $\mathrm{p}<0.05$ \\
\hline$A C V(\mathrm{~mm} / \mathrm{s})$ & $-4.18 \pm 0.18$ & $-3.68 \pm 0.20$ & 0.061 \\
\hline$M C V(\mathrm{~mm} / \mathrm{s})$ & $-4.89 \pm 0.56$ & $-4.64 \pm 0.27$ & 0.066 \\
\hline$A D V(\mathrm{~mm} / \mathrm{s})$ & $1.57 \pm 0.12$ & $1.45 \pm 0.11$ & 0.535 \\
\hline
\end{tabular}

ADHD - Attention Deficit Hyperactivity Disorder, INIT - diameter of the pupil before the application of light stimulus, END - diameter of the pupil at the peak of the constriction, DELTA - percentual change of the pupil diameter during constriction, ACV - average constriction velocity, MCV - maximum constriction velocity, ADV - average dilation velocity. Values are expressed as mean \pm SEM. Probability $\mathrm{p}<0.05$ was considered as significant.

\section{Discussion}

This study firstly revealed discrete abnormalities in PLR indicating subtle impaired central autonomic integrity in ADHD. The parasympathetic subdivision plays a dominant role during the pupil constriction phase, therefore, the PLR represents a non-invasive tool to assess the presence of parasympathetic dysfunction indexed by sensitive parameters, i.e. $\mathrm{MCV}$ and relative constriction amplitude (Wang et al. 2016). From this point of view, reduced parasympathetic activity is characterized by longer constriction latency, slower MCV and smaller constriction amplitude (Lowenstein and Loewenfeld 1950, Loewenfeld and Lowenstein 1999). Thus, our results revealing altered PLR parameters a smaller DELTA related to a slower MCV and ACV 
could indicate deficient parasympathetic activity in pure ADHD. Moreover, both ANS branches innervate the pupil at the beginning of the PLR redilation phase. Pupil redilation has two phases - the early rapid phase is influenced both by parasympathetic withdrawal and sympathetic activation, while the later slower phase of redilation mainly results from sympathetic innervation (Lowenstein and Loewenfeld 1950, Wang et al. 2016). In our study, the PLR parameters reflecting predominantly sympathetic activity were without significant differences between ADHD and controls. Thus, we suggest that ADHD-linked abnormal central autonomic activity is predominantly characterized by parasympathetic underactivity associated with potential relative dominant sympathetic activity. Several mechanisms are assumed. Firstly, the pupillary constriction in response to the light, is regulated at the subcortical level with the EdingerWestphal nucleus, the parasympathetic center for pupillary constriction (Wang et al. 2016), that is modulated by several inputs. Specifically, the EdingerWestphal region receives inhibitory input from sympathetic-linked subcortical structure, locus coeruleus, which gathers most noradrenaline neurons in the brain and has been involved in behavioral flexibility and attention linked to ADHD (Aston-Jones et al. 1999, Darcq and Kieffer 2015).

Moreover, the activity of parasympathetic Edinger-Westphal nucleus is inhibited by the sympathetic locus coeruleus (Wilhelm et al. 1999). The relative sympathetic dominance could represent one of the potential mechanisms leading to altered PLR in ADHD: if activity of sympathetic part of ANS is higher, the neural inhibitory mechanism on Edinger-Westphal region will be excited resulting in dilation of the pupil (Laeng et al. 2012). Thus, diminished pupil reactivity in constriction phase might indicate a relative dominance of central sympathetic control associated with decreased parasympathetic activity at the level of subcortical centers in children with ADHD.

In addition, Edinger-Westphal nucleus is influenced by inhibitory inputs from descending cortical pathways (Steinhauer and Hakerem 1992). It is generally assumed that the prefrontal cortex, modulated by catecholamines, involved in the regulation of attention and working memory (Clark and Noudoost 2014) is hypoactive in ADHD (Cortese 2012, Faraone et al. 2015). Specifically, the catecholamines have influence on prefrontal cortical cognitive functions, whereby too little or too much of dopamine and noradrenaline impair working memory (Brennan and Arnsten 2008). Moreover, the general increase in inhibitory influence involving reticular pathways linked to arousal also impinge on the Edinger-Westphal complex (Bonvallet and Zbrozyna 1963, Steinhauer et al. 2004). Thus, cognitive load associated with frontal and prefrontal cortical functioning mediated by direct cortical and indirect cortico-thalamo-hypothalamic pathways contributes to this inhibitory process resulting in inhibition of the Edinger-Westphal nucleus (Lowenstein 1955, Steinhauer and Hakerem 1992, Steinhauer et al. 2004). In this context, we could hypothesize that hypofunction of prefrontal cortex and subsequent deficient inhibitory influence on subcortical structures including parasympathetic oculomotor complex may contribute to potential mechanism leading to altered PLR.

Moreover, the constrictor muscle of the pupil decreases the pupil diameter under the control of the ciliary ganglion. Both the ciliary ganglion and constrictor muscles contain acetylcholine receptors, which is the main neurotransmitter of the parasympathetic nervous system (Wang et al. 2016). The acetylcholine plays an important role in brain circuits mediating motor control, attention, learning and memory (Perry et al. 1999, Calabresi et al. 2014, Hasselmo and Sarter 2011), which impairments are related to ADHD (Faraone et al. 2015). Previous studies have shown evidence of cholinergic deficits in ADHD (Todd et al. 2003, Lee et al. 2008). Recent reviews have identified numerous candidate genes implicated in ADHD-linked neurotransmission dysregulation (Todd et al. 2003, Lee et al. 2008, Dai et al. 2017). Therefore, our findings of ADHD-linked abnormal PLR could be affected by the complex neurophysiological abnormalities such as genetic variations in neurotransmitters including acetylcholine (Hellmer and Nyström 2017). Specifically, cholinergic gene CHRNA4 that encode $\alpha 4$ subunit of nicotinic acetylcholine receptors is associated with ADHD (Todd et al. 2003, Lee et al. 2008). Thus, it seems that the diminished PLR indicating reduced parasympathetic activity could reflect neurotransmitters' particularly cholinergic dysregulation linked to ADHD.

Furthermore, ADHD patients are characterized by reductions in cerebral volume including prefrontal cortex and subcortical structures such as amygdala, hippocampus, nucleus caudatum, nucleus accumbens and putamen (Emond et al. 2009). Besides these macrostructural alterations, it showed that ADHD is linked to dysregulation of fronto-striatal as well as fronto- 
parietal networks (Bush et al. 2005, Fan and Posner 2004). Notably, fronto-amygdalar circuits could be involved in assignment of emotional valence to events and also inputs from amygdala can influence the recruitment of prefrontal control (Durston et al. 2011). It seems that dysregulated functional communications in these networks are linked to behavioral dysfunction in ADHD (Nagel et al. 2011). In particular, amygdala plays a crucial role in emotional regulation (Schumann et al. 2009) as well as in the central autonomic control via extensive connections with hypothalamus and ventromedial prefrontal cortex (Critchley 2002, Arnsten 2009). Furthermore, the amygdala that has outputs to autonomic, endocrine, and other physiological regulatory systems and becomes active during threat and uncertainty, is under tonic inhibitory control from the prefrontal cortex (Thayer 2006, Davidson et al. 2000). Interestingly, pupil reactivity provides information linked to brain structures included in cognitive-affective regulation. In this context, one of the potential mechanisms leading to altered PLR in ADHD could include impaired reactivity in emotional circuitry (Laeng et al. 2012). Recent study reported that the cortico-limbic circuitry connecting the amygdala with the thalamus and orbital frontal cortex responsible for emotional learning and behavioral regulation is dysfunctional in ADHD (Gehricke et al. 2017). Therefore, it is assumed that complex central network consisting of multiple brain regions and pathways implicated in cognitive-affective regulation could affect pupil reactivity in ADHD.

From neurophysiological view, the PLR is innervated by a new class of photoreceptors called intrinsically photosensitive retinal ganglion cells (ipRGC) that interplay and project via dopaminergic amacrine cell (Hellmer and Nyström 2017). Previous studies demonstrated that disorders caused by dopamine deficiency in retina lead to problems in light accommodation influencing a light adaptive mechanisms (Loewenfeld 1999, Witkovsky 2004, Jackson et al. 2012). Recent experimental study evaluated signaling of retinal dopamine that expresses dopamine transporter coding variant Ala559Val associated with ADHD. The study showed attenuated retinal light responses suggesting one of the underlying mechanism contributing to diminished pupillary reactivity in ADHD (Dai et al. 2017).

Our findings of altered PLR are in accordance with previous studies revealing reduced cardiac vagal control and potential sympathetic overactivity using heart rate variability in untreated children suffering from ADHD (Tonhajzerova et al. 2009, Tonhajzerova et al. 2014). In this context, we assume that abnormalities in mutually interconnected brain areas involved in heart and pupil autonomic control may result in shift of autonomic balance towards a parasympathetic underactivity associated with supposed sympathetic dominance in ADHD. It seems that the PLR examination could provide a crucial information about complex central autonomic network integrity leading to potential abnormalities in the regulation of peripheral effectors in ADHD.

\section{Study limitations}

The limitation of our study is relatively small homogeneous group of patients with ADHD, therefore, the findings of this study need to be independently validated in larger groups of patients with respect to gender differences. In addition, the simultaneous assessment of other physiological biosignals reflecting autonomic regulation (e.g. heart rate and blood pressure variability, electrodermal response, etc.) could illuminate the pathway of the pathomechanisms leading to complex autonomic dysregulation in ADHD. Moreover, the study of interaction between cognitive functioning (memory, learning) and PLR impairment may provide an important information about psychophysiological/neurobiological changes in ADHD. Further research in this field is needed.

\section{Conclusions}

Our study revealed that ADHD is characterized by discrete abnormal central autonomic regulation in the manner of parasympathetic underactivity and relative sympathetic dominance. Further research including the evaluation of peripheral autonomic effectors' activity could bring novel knowledge regarding central-peripheral pathophysiological pathways linked to ADHD.

\section{Conflict of Interest}

There is no conflict of interest.

\section{Acknowledgements}

This study was supported by the Scientific Grant Agency under grant VEGA 1/0044/18, VEGA 1/0190/20 and by the project "Biomedical Center Martin" ITMS code: 26220220187, co-financed from EU sources. 


\section{References}

AMERICAN PSYCHIATRIC ASSOCIATION: Diagnostic and Statistical Manual of Mental Disorders DSM-5. Fifth Edition. American Psychiatric Association, Arlington, 2013, 947 p. https://doi.org/10.1176/appi.books.9780890425596

ARNSTEN AF: Toward a new understanding of attention-deficit hyperactivity disorder pathophysiology. CNS Drugs 23: 33-41, 2009. https://doi.org/10.2165/00023210-200923000-00005

ASTON-JONES G, RAJKOWSKI J, COHEN J: Role of locus coeruleus in attention and behavioral flexibility. Biol Psych 46: 1309-1320, 1999. https://doi.org/10.1016/S0006-3223(99)00140-7

BÄR KJ, BOETTGER MK, TILL S, DOLICEK J, SAUER H: Lateralization of pupillary light reflex parameters. Clin Neurophysiol 116: 790-798, 2005. https://doi.org/10.1016/j.clinph.2004.11.007

BINDA P, PEREVERZEVA M, MURRAY SO: Attention to bright surfaces enhances the pupillary light reflex. J Neurosci 33: 2199-2204, 2013. https://doi.org/10.1523/JNEUROSCI.3440-12.2013

BONVALLET B, ZBROZYNA A: Reticular control of the autonomic system, and particularly, the sympathetic and parasympathetic innervation of the pupil. Arch Ital Biol 101: 174-207, 1963.

BRENNAN AR, ARNSTEN AF: Neuronal mechanisms underlying attention deficit hyperactivity disorder. Ann NY Acad Sci 1129: 236-245, 2008. https://doi.org/10.1196/annals.1417.007

BUSH G, VALERA EM, SEIDMAN LJ: Functional neuroimaging of attention-deficit/hyperactivity disorder: a review and suggested future directions. Biol Psychiatry 57: 1273-1284, 2005. https://doi.org/10.1016/j.biopsych.2005.01.034

CALABRESI P, PICCONI B, TOZZI A, GHIGLIERI V, DI PHILIPPO M: Direct and indirect pathways of basal ganglia: a critical reappraisal. Nat Neurosci 17: 1022-1030, 2014. https://doi.org/10.1038/nn.3743

CLARK KL, NOUDOOST B: The role of prefrontal catecholamines in attention and working memory. Front Neural Circuits 8: 33, 2014. https://doi.org/10.3389/fncir.2014.00033

CORTESE S: The neurobiology and genetics of Attention-Deficit/HyperactivityDisorder (ADHD): What every clinician should know. Eur Jour Paediatr Neurol 16: 422-433, 2012. https://doi.org/10.1016/j.ejpn.2012.01.009

CRITCHLEY HD: Review: electrodermal responses: what happens in the brain. Neurosci 8: 132-142, 2002. https://doi.org/10.1177/107385840200800209

CROWELL SE, BEAUCHAINE TP, GATZKE-KOPP L, SYLVERS PD, MEAD H, CHIPMAN-CHACON J: Autonomic correlates of attention-deficit/hyperactivity disorder and oppositional defiant disorder in preschool children. J Abnorm Psychol 115: 174-178, 2006. https://doi.org/10.1037/0021-843X.115.1.174

DAI H, JACKSON CH, DAVIS GL, BLAKELY RD, MCMAHON DG: Is dopamine transporter-mediated dopaminergic signaling in the retina a noninvasive biomarker for attention-deficit/ hyperactivity disorder? A study in a novel dopamine transporter variant Val559 transgenic mouse model. J Neurodev Disord 9: 1, 2017. https://doi.org/10.1186/s11689-017-9215-8

DARCQ E, KIEFFER BL: PI3K signaling in the locus coeruleus: a new molecular pathway for ADHD research. EMBO Mol Med 7: 859-861, 2015. https://doi.org/10.15252/emmm.201505266

DAVIDSON RJ, JACKSON DC, KALIN NH: Emotion, plasticity, context, and regulation: Perspectives from affective neuroscience. Psychol Bull 126: 890-909, 2000. https://doi.org/10.1037/0033-2909.126.6.890

DURSTON S, VAN BELLE J, DE ZEEUW P: Differentiating frontostriatal and fronto-cerebellar circuits in attention-deficit/hyperactivity disorder. Biol Psychiatry 69: 1178-1184, 2011. https://doi.org/10.1016/j.biopsych.2010.07.037

EMOND V, JOYAL C, POISSANT H: Structural and functional neuroanatomy of attention-deficit hyperactivity disorder (ADHD): Encephale 35: 107-114, 2009. https://doi.org/10.1016/j.encep.2008.01.005

FAN J, POSNER M: Human attentional networks. Psychiatr Prax 31 (Suppl 2): S210-S214, 2004. https://doi.org/10.1055/s-2004-828484

FARAONE SV, ASHERSON P, BANASCHEWSKI T, BIEDERMAN J, BUITELAAR JK, RAMOS-QUIROGA JA, ROHDE LA, SONUGA-BARKE EJ, TANNOCK R, FRANKE B: Attention-deficit/hyperactivity disorder. Nat Rev Dis Primers 1: 15020, 2015. https://doi.org/10.1038/nrdp.2015.20 
GEHRICKE JG, KRUGGEL F, THAMPIPOP T, ALEJO SD, TATOS E, FALLON J, MUFTULER LT: The brain anatomy of attention-deficit/hyperactivity disorder in young adults - a magnetic resonance imaging study. PLoS One 12: e0175433, 2017. https://doi.org/10.1371/journal.pone.0175433

HALL CA, CHILCOTT RP: Eyeing up the future of the pupillary light reflex in neurodiagnostics. Diagnostics 8: 19, 2018. https://doi.org/10.3390/diagnostics8010019

HASSELMO ME, SARTER M: Modes and models of forebrain cholinergic neuromodulation of cognition. Neuropsychopharmacol 36: 52-73, 2011. https://doi.org/10.1038/npp.2010.104

HELLMER K, NYSTRÖM P: Infant acetylcholine, dopamine, and melatonin dysregulation: Neonatal biomarkers and causal factors for ASD and ADHD phenotypes. Med Hypotheses 100: 64-66, 2017. https://doi.org/10.1016/j.mehy.2017.01.015

JACKSON CR, RUAN GX, ASEEM F, ABEY J, GAMBLE K, STANWOOD G, MCMAHON DG: Retinal dopamine mediates multiple dimensions of light-adapted vision. J Neurosci 32: 9359-9368, 2012. https://doi.org/10.1523/JNEUROSCI.0711-12.2012

KARA K, KARAMAN D, ERDEM U, CONGOLOGLU MA, DURUKAN I, ILHAN A: Investigation of autonomic nervous system functions by pupillometry in children with attention deficit hyperactivity disorder. Bull Clin Psychopharmacol 23: 49-56, 2013. https://doi.org/10.5455/bcp.20121130085850

KÖLES M: A review of pupillometry for human-computer interaction studies. Period Polytech Electr Eng Comput Sci 61: 320-326, 2017. https://doi.org/10.3311/PPee.10736

LAENG B, SIROIS S, GREDEBÄCK G: Pupillometry: a window to the preconscious? Perspect Psychol Sci 7: 18-27, 2012. https://doi.org/10.1177/1745691611427305

LAZZARO I, GORDON E, LI W, LIM CL, PLAHN M, WHITMONT S, CLARKE S, BARRY RJ, DOSEN A, MEARES R: Simultaneous EEG and EDA measures in adolescent attention deficit hyperactivity disorder. Int J Psychophysiol 34: 123-134, 1999. https://doi.org/10.1016/S0167-8760(99)00068-9

LEE J, LAURIN N, CROSBIE J, ICKOWICZ A, PATHARE T, MALONE M, KENNEDY JL, TANNOCK R, SCHACHAR R, BARR CL: Association study of the nicotinic acetylcholine receptor alpha4 subunit gene, CHRNA4, in attention-deficit hyperactivity disorder. Genes Brain Behav 7: 53-60, 2008. https://doi.org/10.1111/j.1601-183X.2007.00325.X

LOEWENFELD IE, LOWENSTEIN O: The Pupil: Anatomy, Physiology, and Clinical Applications. ButterworthHeinemann, Woburn, Massachusetts, USA, 1999, 1590 p.

LOWENSTEIN O, LOEWENFELD IE: Mutual role of sympathetic and parasympathetic in shaping of the pupillary reflex to light. Arch Neurol Psychiatr 64: 341-377, 1950. https://doi.org/10.1001/archneurpsyc.1950.02310270030002

LOWENSTEIN O: Pupillary reflex shapes and topical clinical diagnosis. Neurology 5: 631-631, 1955. https://doi.org/10.1212/WNL.5.9.631

MCDOUGAL DH, GAMLIN PD: Autonomic control of the eye. Compr Physiol 5: 439-473, 2015. https://doi.org/10.1002/cphy.c140014

MESTANIKOVA A, ONDREJKA I, MESTANIK M, CESNEKOVA D, VISNOVCOVA Z, BUJNAKOVA I, OPPA M, CALKOVSKA A, TONHAJZEROVA I: Pupillary light reflex is altered in adolescent depression. Physiol Res 66 (Suppl 2): S277-S284, 2017. https://doi.org/10.33549/physiolres. 933683

NAGEL BJ, BATHULA D, HERTING M, SCHMITT C, KROENKE CD, FAIR D, NIGG JT: Altered white matter microstructure in children with attention-deficit/hyperactivity disorder. J Am Acad Child Adolesc Psychiatry 50: 283-292, 2011. https://doi.org/10.1016/j.jaac.2010.12.003

PERRY E, WALKER M, GRACE J, PERRY R: Acetylcholine in mind: a neurotransmitter correlate of consciousness? Trends Neurosci 22: 273-280, 1999. https://doi.org/10.1016/S0166-2236(98)01361-7

SEKANINOVA N, MESTANIK M, MESTANIKOVA A, HAMRAKOVA A, TONHAJZEROVA I: Novel approach to evaluate central autonomic regulation in attention deficit/hyperactivity disorder (ADHD). Physiol Res 68: 531-545, 2019. https://doi.org/10.33549/physiolres. 934160

SHIBAGAKI M, YAMANAKA T, FURUYA T: Attention state in electrodermal activity during auditory stimulation of children with attention-deficit hyperactivity disorder. Percept Mot Skills 77: 331-338, 1993. https://doi.org/10.2466/pms.1993.77.1.331 
SCHUMANN CM, BARNES CC, LORD C, COURCHESNE E: Amygdala enlargement in toddlers with autism related to severity of social and communication impairments. Biol Psychiatry 66: 942-949, 2009. https://doi.org/10.1016/j.biopsych.2009.07.007

STEINHAUER SR, HAKEREM G: The pupillary response in cognitive psychophysiology and schizophrenia. Ann N Y Acad Sci 658: 182-204, 1992. https://doi.org/10.1111/j.1749-6632.1992.tb22845.x

STEINHAUER SR, SIEGLE GJ, CONDRAY R, PLESS M: Sympathetic and parasympathetic innervation of pupillary dilation during sustained processing. Int J Psychophysiol 52: 77-86, 2004. https://doi.org/10.1016/j.ijpsycho.2003.12.005

THAYER JF: The importance of inhibition central and peripheral manifestations of nonlinear inhibitory processes in neural systems. Dose Response 4: 2-21, 2006. https://doi.org/10.2203/dose-response.004.01.002.Thayer

TODD RD, LOBOS EA, SUN LW, NEUMAN RJ: Mutational analysis of the nicotinic acetylcholine receptor alpha 4 subunit gene in attention deficit/hyperactivity disorder: Evidence for association of an intronic polymorphism with attention problems. Mol Psychiatry 8: 103-108, 2003. https://doi.org/10.1038/sj.mp.4001257

TONHAJZEROVA I, ONDREJKA I, ADAMIK P, HRUBY R, JAVORKA M, TRUNKVALTEROVA Z, MOKRA D, JAVORKA K: Changes in the cardiac autonomic regulation in children with attention deficit hyperactivity disorder (ADHD). Indian J Med Res 130: 44-50, 2009.

TONHAJZEROVA I, ONDREJKA I, FARSKY I, VISNOVCOVA Z, MESTANIK M, JAVORKA M, JURKO A JR, CALKOVSKA A: Attention deficit/hyperactivity disorder (ADHD) is associated with altered heart rate asymmetry. Physiol Res 63: 509-519, 2014. https://doi.org/10.33549/physiolres.932919

WANG Y, ZEKVELD AA, NAYLER G, OHLENFORST B, JANSMA EP, LORENS A, LUNNER T, KRAMER SE: Parasympathetic nervous system dysfunction, as identified by pupil light reflex, and its possible connection to hearing impairment. PLoS One 11: e0153566, 2016. https://doi.org/10.1371/journal.pone.0153566

WILHELM B, WILHELM H, LÜDTKE H: Pupillography: Principles and applications in basic and clinical research. In: Pupillography: Principles, Methods and Applications. KUHLMANN J, BOTTCHER M (eds), Zuckschwerdt Verlag, München, 1999, pp 1-11.

WITKOVSKY P: Dopamine and retinal function. Doc Opthalmol 108: 17-40, 2004. https://doi.org/10.1023/B:DOOP.0000019487.88486.0a

ZAHN TP, LITTLE BC, WENDER PH: Pupillary and heart rate reactivity in children with minimal brain dysfunction. J Abnorm Child Psychol 6: 135-147, 1978. https://doi.org/10.1007/BF00915789 